Article

\title{
Association between duration of deep hypothermic circulatory arrest and surgical outcome in patients with acute type A aortic dissection: A large retrospective cohort study
}

\author{
Mona Salehi Ravesh ${ }^{1,4}$, Christine Friedrich ${ }^{2,4}$, Jan Schoettler ${ }^{2}$, Lars Hummitzsch ${ }^{3}$, Gunnar Elke ${ }^{3}$, Mohamed Salem ${ }^{2}$, \\ Georg Lutter ${ }^{2,4}$, Thomas Puehler ${ }^{2,4}$, Jochen Cremer ${ }^{2}$, and Assad Haneya ${ }^{2}$
}

\#: Dr. Mona Salehi Ravesh and Christine Friedrich contributed equally to this work

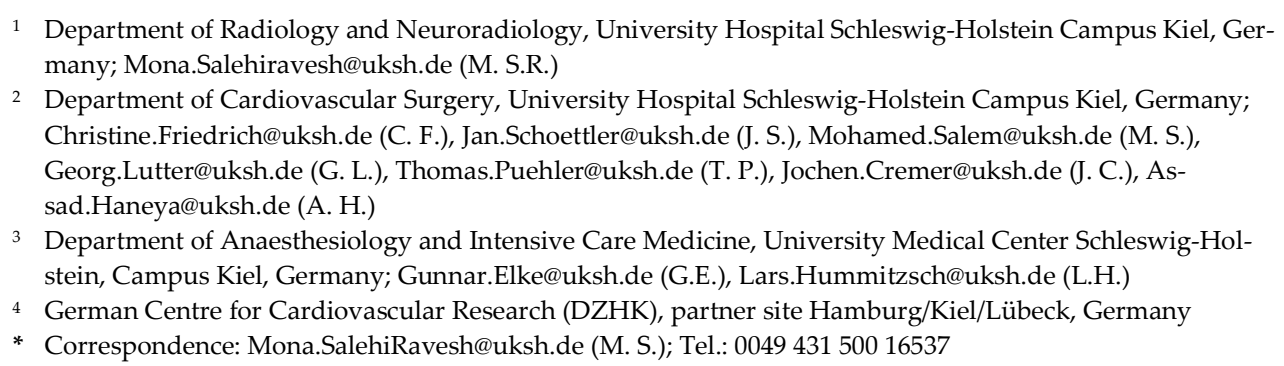

\begin{abstract}
Background: Deep hypothermic circulatory arrest (DHCA) with selective antegrade cerebral perfusion (ACP) is an established cerebral protection technique for the conduction of complex surgical procedures involving the aortic arch. It is controversial if the duration of DHCA is associated with adverse outcome in patients with acute type A aortic dissection (AAAD). Our goal was to investigate whether DHCA time was associated with surgical outcome in patients undergoing a surgical treatment of AAAD. (2) Methods: 410 Patients were divided into two groups concerning the DHCA time less than 60 minutes and equal or longer than 60 minutes. (3) Results: Patients with longer DHCA time were significantly younger $(p=0.001)$. Intraoperatively, complex procedures with aortic arch surgery were more common in patients with longer DHCA time $(p<0.001)$. Accordingly, cardiopulmonary bypass $(\mathrm{p}<0.001)$, cross-clamping $(\mathrm{p}<0.001)$ and DHCA times $(\mathrm{p}<0.001)$ were significantly longer in this group. Postoperatively, only the duration of mechanical ventilation $(p<0.001)$ and the rate of tracheotomy were significantly higher in these patients. 30-day mortality was satisfactory for both groups $(p=0.746)$. (4) Conclusions: Our results showed that improvements in perioperative management including ACP allow a successful performance of surgical treatment of AAAD under DHCA with duration of even longer than 60 minutes.
\end{abstract}

Keywords: Deep hypothermic circulatory arrest time, acute type A aortic dissection, surgical outcome.

\section{Introduction}

Cerebral complications are a predominant cause of mortality and morbidity after thoracic aortic surgery [1]. In the mid-1970s, the first experience with applying deep hypothermic circulatory arrest (DHCA) to protect the central nervous system during a complex surgical procedure for the replacement of the aortic arch was reported [2]. DHCA with adjunctive selective antegrade cerebral perfusion (SACP) supports the protection of the central nervous system during a prolonged period of circularly arrest (more than 30 
minutes) [3]. Moreover, cerebral perfusion using antegrade and retrograde cerebral perfusion strategies during hypothermic circulatory arrest are associated with reduced death and stroke risk [4].

Despite the benefits of DHCA with SACP for vital organ support during complex cardiac surgery, some centers do not prefer its use to avoid the potential adverse impact of prolonged duration of circulatory arrest on postoperative renal function [5]. It is controversial if only the grade of hypothermia, the duration of DHCA or a combination of pre-, intra-, and postoperative factors is associated with mortality in patients $[6,7]$.

The aim of the present study was to investigate whether DHCA time is associated with clinical outcome of patients undergoing surgical treatment of acute type A aortic dissection (AAAD).

\section{Materials and Methods}

\subsection{Patients and study design}

Between January 2001 and May 2019, a total of 410 consecutive patients underwent a surgical treatment of an AAAD using DHCA and ACP. Patients were divided into two groups: those with a DHCA time less than 60 minutes $(n=337 ; 82.2 \%)$ and those with a DHCA time equal or longer than 60 minutes $(n=73 ; 17.8 \%)$.

Preoperatively, contrast enhanced computed tomography (CT) was performed to detect the exact location and extension of the dissection membrane. In a few cases, the aortic dissection was discovered incidentally during magnetic resonance imaging (MRI) or coronary angiography examination or was detected during coronary angiography in patients with iatrogenic dissections. Postoperatively, patients were examined for neurological symptoms and questioned at admission for any history of neurological events. Neurological complications were consulted directly by a neurologist and categorized according to neurological assessment, followed by head and neck CT as well as, in many cases, CT angiography for the carotid arteries to estimate the extent of stroke and brain ischemia.

The primary endpoints were 30-day mortality and postoperative neurological events. Secondary endpoints were pre- and intraoperative variables, as well as the postoperative courses such as blood loss and transfusion of blood products.

\subsection{Operative Technique}

After a standard median sternotomy, cardiopulmonary bypass (CPB) was performed with DHCA with a nasopharyngeal temperature between $20-24^{\circ} \mathrm{C}$. Venous cannulation was performed either through the femoral vein or the right atrium. Until 2010, depending on the pathology and the extent of the dissection, the arterial cannulation was performed either through the distal ascending aorta or the femoral artery. Since 2010, the standard approach in our center is the cannulation of the left ventricle transatrial via the right upper pulmonary. [8]. Retrograde blood cardioplegic solution was used for myocardial protection. Antegrade cerebral perfusion with oxygenated cold blood $\left(18^{\circ} \mathrm{C}\right)$ was introduced through a balloon catheter inserted bilateral in arch vessels with a pressure control of 50$60 \mathrm{mmHg}$. Once the distal anastomosis was completed, de-airing was performed by restarting retrograde perfusion through the venous cannula, followed by slow antegrade perfusion of the newly cannulated prosthesis. During rewarming, appropriate procedures for the aortic root and the aortic valve were performed. Transfusion trigger was defined as that value of haemoglobin $(\mathrm{Hb})$ below $10 \mathrm{gm} / \mathrm{dL}$. Perioperatively, neuromonitoring with near-infrared spectroscopy (NIRS) was applied. The operative technique has been described in more detail in previous papers $[9,10]$.

\subsection{Statistical Analysis}


The statistical analysis was performed with IBM SPSS statistics (version 28.0). The frequency distribution of the sample data was examined for deviations from the normal distribution using the Kolmogorov-Smirnov-Lilliefors-test. The mean \pm standard deviation was given for normally distributed, continuous variables, while not-normally distributed continuous variables were displayed as median with associated quartiles. Categorical variables were presented as absolute number of affected patients (n) and the corresponding percentage (\%). The Chi-square test and, if necessary, the exact Fisher test were used to compare categorial variables of the two groups examined, while Mann-WhitneyU-test was applied to compare not-normally distributed continuous and ordinal variables. Survival was estimated on right-censored data of 30-day survivors by Kaplan-Meier method and compared for differences by log rank test. All p-values $\leq 0.05$ were rated as a significant difference between the two groups. Missing values were excluded pairwise and missing data $>5 \%$ are indicated in the tables.

\section{Results}

\subsection{Demographics and clinical characteristics of the study population}

Relevant demographics and preoperative data of the study participants are presented in Table 1. Patient with longer DHCA time were significantly younger $(58.0 \pm 12.9$ vs. $63.2 \pm 12.8$ years, $\mathrm{p}=0.001$ ) and frequently belonged to DeBakey type I (233 vs. 69, $\mathrm{p}<0.001)$. A lower percentage of these patients was female $(23.3 \%$ vs. $37.7 \%, p=0.019)$. Otherwise, there were no in-between group differences concerning preoperative data.

Table 1: Demographic and clinical characteristics of the study population

\begin{tabular}{|c|c|c|c|c|}
\hline Variable & Total & $\begin{array}{c}\text { Cardiac ar- } \\
\text { rest } \\
<60 \mathrm{~min} \\
\end{array}$ & $\begin{array}{c}\text { Cardiac ar- } \\
\text { rest } \\
\geq 60 \mathrm{~min}\end{array}$ & $\begin{array}{c}\mathrm{p}- \\
\text { value }\end{array}$ \\
\hline Number of surgical procedures, n (\%) & $\begin{array}{c}410(100 \%) \\
62.3 \pm 13.0\end{array}$ & $\begin{array}{c}337(82.2 \%) \\
63.2 \pm 12.8\end{array}$ & $\begin{array}{c}73(17.8 \%) \\
58.0 \pm 12.9\end{array}$ & $\begin{array}{c}--- \\
0.001\end{array}$ \\
\hline Age, mean \pm standard deviation years & $\begin{array}{c}63.0 \\
(53.0 ; 72.3)\end{array}$ & $65(54.5 ; 73.0)$ & $57(49.5 ; 66.5)$ & \\
\hline Female, n (\%) & $144(35.1 \%)$ & $127(37.7 \%)$ & $17(23.3 \%)$ & 0.019 \\
\hline EuroSCORE II & $6.0(3.8 ; 13.1)$ & $6.2(4.0 ; 13.4)$ & $5.9(3.1 ; 9.9)$ & 0.065 \\
\hline Body mass index $\left(\mathrm{kg} / \mathrm{m}^{2}\right)$ & $\begin{array}{c}26.2 \\
(23.9 ; 29.0)\end{array}$ & $\begin{array}{c}26.2 \\
(23.9 ; 28.9)\end{array}$ & $\begin{array}{c}25.8 \\
(23.9 ; 29.3)\end{array}$ & 0.902 \\
\hline DeBakey 1, 6.1\% missing, n (\%) & $301(78.2 \%)$ & $233(74.0 \%)$ & $68(97.1 \%)$ & $<0.001$ \\
\hline Arterial hypertension, n (\%) & $278(67.8 \%)$ & $228(67.7 \%)$ & $50(68.5 \%)$ & 0.890 \\
\hline Pulmonary hypertension, n (\%) & $7(1.7 \%)$ & $6(1.8 \%)$ & $1(1.4 \%)$ & 1.000 \\
\hline Type 2 Diabetes mellitus, n (\%) & $20(4.9 \%)$ & $19(5.6 \%)$ & $1(1.4 \%)$ & 0.225 \\
\hline Insulin dependent, $\mathbf{n}(\mathbf{\%})$ & $6(1.5 \%)$ & $6(1.8 \%)$ & $0(0.0 \%)$ & 0.596 \\
\hline Hyperlipoproteinaemia, n (\%) & $46(11.2 \%)$ & $39(11.6 \%)$ & $7(9.6 \%)$ & 0.621 \\
\hline Neurological deficits, n (\%) & $77(18.8 \%)$ & $64(19.0 \%)$ & $13(17.8 \%)$ & 0.815 \\
\hline Chronic renal failure/insufficiency, n (\%) & $48(11.7 \%)$ & $39(11.6 \%)$ & $9(12.3 \%)$ & 0.855 \\
\hline Renal replacement therapy, n (\%) & $7(1.7 \%)$ & $5(1.5 \%)$ & $2(2.7 \%)$ & 0.613 \\
\hline COPD, n (\%) & $29(7.1 \%)$ & $24(7.1 \%)$ & $5(6.8 \%)$ & 0.934 \\
\hline Coronary heart disease, $\mathrm{n}(\%)$ & $69(16.8 \%)$ & $58(17.2 \%)$ & $11(15.1 \%)$ & 0.657 \\
\hline \multicolumn{5}{|l|}{ Heart rhythm, n (\%) } \\
\hline Atrial fibrillation, $\mathbf{n}(\mathbf{\%})$ & $55(13.4 \%)$ & $47(13.9 \%)$ & $8(11.0 \%)$ & 0.497 \\
\hline Previous PCI, n (\%) & $26(6.4 \%)$ & $20(6.0 \%)$ & $6(8.2 \%)$ & 0.435 \\
\hline Previous cardiac surgery, n (\%) & $35(8.5 \%)$ & $27(8.0 \%)$ & $8(11.0 \%)$ & 0.414 \\
\hline Peripheral vascular disease, n (\%) & $14(3.4 \%)$ & $12(3.6 \%)$ & $2(2.7 \%)$ & 1.000 \\
\hline LVEF (\%) & $60(55 ; 70)$ & $60(55 ; 70)$ & $66(55 ; 70)$ & 0.342 \\
\hline
\end{tabular}


Marfan syndrome, $\mathbf{n}(\%)$

Diagnostic imaging using

Diameter of aorta (mm)

Calcific aortic disease, $\mathbf{n}(\%)$

Bicuspid aortic valve, $\mathrm{n}(\%)$

Aortic valve vitium, n (\%)

Aortic valve stenosis, n (\%)

Aortic valve insufficiency, $\mathbf{n}(\mathbf{\%})$

Combined Aortic valve vitium at Aortic valve replacement, n (\%)

Clinical presentation

Acute myocardial infarction (48h), n (\%)

Cardiogenic shock, n (\%)

CPR, n (\%)

Transfer from intensive care unit, $\mathbf{n}(\%)$

Intubated, $\mathbf{n}(\%)$

$\begin{array}{cccc}359(88.0 \%) & 297(88.7 \%) & 62(84.9 \%) & 0.375 \\ 128(31.3 \%) & 108(32.1 \%) & 20(27.4 \%) & 0.428 \\ 6(1.5 \%) & 5(1.5 \%) & 1(1.4 \%) & 1.000 \\ 9(2.2 \%) & 6(1.8 \%) & 3(4.1 \%) & 0.205 \\ 50(46 ; 60) & 50(46 ; 60) & 50(42 ; 60) & 0.508 \\ 8(2.0 \%) & 8(2.4 \%) & 0(0.0 \%) & 0.360 \\ 20(5.0 \%) & 18(5.5 \%) & 2(2.8 \%) & 0.549 \\ 159(40.2 \%) & 141(43.1 \%) & 18(26.1 \%) & 0.009 \\ 11(2.8 \%) & 10(3.1 \%) & 1(1.4 \%) & 0.698 \\ 141(35.6 \%) & 126(38.5 \%) & 15(21.7 \%) & 0.008 \\ 7(1.8 \%) & 5(1.5 \%) & 2(2.9 \%) & 0.352 \\ & & & \\ 14(3.4 \%) & 12(3.6 \%) & 2(2.7 \%) & 1.000 \\ 30(7.3 \%) & 26(7.7 \%) & 4(5.5 \%) & 0.502 \\ 31(7.6 \%) & 27(8.0 \%) & 4(5.5 \%) & 0.458 \\ 47(11.5 \%) & 40(11.9 \%) & 7(9.6 \%) & 0.579 \\ 43(10.5 \%) & 37(11.0 \%) & 6(8.2 \%) & 0.481\end{array}$

$43(10.5 \%)$

$37(11.0 \%)$

$6(8.2 \%)$

0.481

Significant $\mathrm{p}$-values are indicated in bold. Quantitative data are presented as median with $25^{\text {th }}$ and $75^{\text {th }}$ percentiles. The symbol $\mathrm{n}$ indicates the number of patients in categorical data. The European System for Cardiac Operative Risk Evaluation is abbreviated to EuroSCORE, chronic obstructive pulmonary disease to COPD, percutaneous coronary intervention to PCI, left ventricle to $\mathbf{L V}$, ejection fraction to $\mathbf{E F}$, and c-reactive protein to CPR.

\subsection{Intraoperative data}

Intraoperatively, complex procedures with total aortic arch replacement were significantly more common in patients with longer DHCA time $(64.4 \%$ vs. $3.6 \%$; p $<0.001)$. Accordingly, cardiopulmonary bypass time [245 vs. 154 minutes; $\mathrm{p}<0.001$ ], cross-clamping time [145 vs. 83 minutes; $\mathrm{p}<0.001$ ] and DHCA times [ 88 vs. 30 minutes; $\mathrm{p}<0.001$ ] were significantly longer due to the complexity of the performed surgical procedures (Table 2).

Moreover, total number of received packed red blood cells (6 vs. 3, $\mathrm{p}=0.001$ ), fresh frozen plasma ( 4 vs. $0, p=0.002)$, and platelet concentrate ( 2 vs. $0, p<0.001)$ was administered significantly more often in this patient group.

Table 2: Intraoperative data

\begin{tabular}{lcccc}
\hline Variable & Total & Cardiac arrest & Cardiac arrest & p-value \\
& & $<60 \mathrm{~min}$ & $\geq 60 \mathrm{~min}$ & \\
\hline Duration of surgery, min & $277(229 ; 340)$ & $255(220 ; 311)$ & $358(304 ; 421)$ & $<\mathbf{0 . 0 0 1}$ \\
Cardiopulmonary bypass time, $\mathbf{m i n}$ & $166(136 ; 210)$ & $154(131 ; 190)$ & $245(206 ; 296)$ & $<\mathbf{0 . 0 0 1}$ \\
Cross-clamp time, min & $92(71 ; 130)$ & $83(67 ; 109)$ & $145(120 ; 202)$ & $<\mathbf{0 . 0 0 1}$ \\
Circulatory arrest, min & $33(26 ; 49)$ & $30(24 ; 38)$ & $88(70 ; 129)$ & $<\mathbf{0 . 0 0 1}$ \\
Number of packed red blood cells, units & $2(0 ; 6)$ & $2(0 ; 5)$ & $4(0 ; 7.5)$ & $\mathbf{0 . 0 1 9}$ \\
Number of fresh frozen plasma, units & $0(0 ; 6)$ & $0(0 ; 4)$ & $4(0 ; 6)$ & $\mathbf{0 . 0 2 3}$ \\
Number of platelet concentrate, units & $2(1 ; 2)$ & $2(1 ; 2)$ & $2(1 ; 2)$ & $\mathbf{0 . 0 0 5}$ \\
Surgical procedure & & & $7(9.6 \%)$ & $<\mathbf{0 . 0 0 1}$ \\
$\quad$ Supracoronary replacement $\mathbf{n} \mathbf{( \% )}$ & $194(47.3 \%)$ & $187(55.5 \%)$ & $18(24.7 \%)$ & 0.835 \\
$\quad$ Partial arch replacement $\mathbf{n} \mathbf{( \% )}$ & $79(23.7 \%)$ & $79(23.5 \%)$ & $47(64.4 \%)$ & $<\mathbf{0 . 0 0 1}$
\end{tabular}




\begin{tabular}{|c|c|c|c|c|}
\hline Conduit/Bentall operation $\mathbf{n}(\mathbf{\%})$ & $82(20.0 \%)$ & $64(19.0 \%)$ & $18(24.7 \%)$ & 0.273 \\
\hline David operation $\mathbf{n}(\mathbf{\%})$ & $22(5.4 \%)$ & $18(5.3 \%)$ & $4(5.5 \%)$ & 1.000 \\
\hline Elephant-trunk n (\%) & $9(2.2 \%)$ & $0(0.0 \%)$ & $9(12.3 \%)$ & $<0.001$ \\
\hline Additional CABG n (\%) & $31(7.6 \%)$ & $29(8.6 \%)$ & $2(2.7 \%)$ & 0.086 \\
\hline Additional aortic valve replacement $\mathbf{n}(\mathbf{\%})$ & $77(18.8 \%)$ & $62(18.4 \%)$ & $15(20.5 \%)$ & 0.670 \\
\hline \multicolumn{5}{|l|}{ Interventional procedure } \\
\hline TEVAR (EVAR), n (\%) & $27(6.6 \%)$ & $17(5.0 \%)$ & $10(13.7 \%)$ & 0.015 \\
\hline \multicolumn{5}{|l|}{ Arterial cannulation } \\
\hline Femoral artery, n (\%) & $73(17.8 \%)$ & $67(19.9 \%)$ & $6(8.2 \%)$ & 0.018 \\
\hline Ascending aorta, n (\%) & $90(22.0 \%)$ & $71(21.1 \%)$ & $19(16.0 \%)$ & 0.353 \\
\hline Aortic arch, n (\%) & $11(2.7 \%)$ & $11(3.3 \%)$ & $0(0.0 \%)$ & 0.225 \\
\hline Subclavian artery, n (\%) & $1(0.2 \%)$ & $0(0.0 \%)$ & $1(1.4 \%)$ & 0.178 \\
\hline Apex, n (\%) & $5(1.2 \%)$ & $4(1.2 \%)$ & $1(1.4 \%)$ & 1.000 \\
\hline Pulmonary vein, n (\%) & $230(56.1 \%)$ & $184(54.6 \%)$ & $46(63.0 \%)$ & 0.189 \\
\hline \multicolumn{5}{|l|}{ Venous cannulation } \\
\hline Right atrium, n (\%) & $399(97.3 \%)$ & $329(97.6 \%)$ & $70(95.9 \%)$ & 0.421 \\
\hline Bicaval, n (\%) & $4(1.0 \%)$ & $1(0.3 \%)$ & $3(4.1 \%)$ & 0.019 \\
\hline Femoral vein, $\mathbf{n}(\mathbf{\%})$ & $7(1.7 \%)$ & $7(2.1 \%)$ & $0(0.0 \%)$ & 0.361 \\
\hline
\end{tabular}

Significant $\mathrm{p}$-values are indicated in bold. Quantitative data are presented as median with $25^{\text {th }}$ and $75^{\text {th }}$ percentiles. The symbol $\mathrm{n}$ indicates the number of patients in categorical data. Coronary artery bypass graft surgery to CABG, thoracic endovascular aortic repair to TEVAR, millimeter to $\mathbf{m m}$, and endovascular aortic repair to EVAR.

\subsection{Postoperative data and outcomes}

Also postoperatively, the total number of received packed red blood cells $(6(2 ; 16)$ vs. $3(0 ; 7)$ unit, $\mathrm{p}=0.001)$, fresh frozen plasma $(4(0 ; 12)$ vs. $0(0 ; 6)$ unit, $\mathrm{p}=0.002)$, and platelet concentrate $(2(0 ; 3)$ vs. $0(0 ; 2)$ unit; $\mathrm{p}<0.001)$ was significantly higher in patients with longer DHCA time (Table 3). These patients required a significantly higher rate of re-intubation $(26.0 \%$ vs. $15.4 \%, \mathrm{p}=0.030)$ and tracheotomy $(43.8 \%$ vs. $20.2 \%, \mathrm{p}<0.001)$ with higher duration of mechanical ventilation (134 vs 50 minutes, $\mathrm{p}<0.001)$ and duration of stay in ICU $(9(4 ; 19)$ vs. $5(2 ; 10)$ days). Patients undergoing longer DHCA presented a not significant higher rate of postoperative neurological deficits (31.5\% vs $21.4 \%, \mathrm{p}=0.06)$. Moreover, there was no difference between both groups concerning the postoperative complications and 30-day mortality (15.1\% vs. $16.6 \%$; $=0.746)$.

Table 3: Postoperative data and outcomes

\begin{tabular}{|c|c|c|c|c|}
\hline Variable & Total & $\begin{array}{c}\text { Cardiac arrest } \\
<60 \mathrm{~min}\end{array}$ & $\begin{array}{c}\text { Cardiac arrest } \\
\geq 60 \mathrm{~min}\end{array}$ & p-value \\
\hline New-onset of Hemodialysis, n (\%) & $89(21.8 \%)$ & $70(20.8 \%)$ & $19(26.0 \%)$ & 0.330 \\
\hline $48 \mathrm{~h}$-drainage loss, $\mathrm{ml}$ & $900(500 ; 1500)$ & $850(450 ; 1425)$ & $1000(650 ; 1825)$ & 0.024 \\
\hline Rethoracotomy, n (\%) & $76(18.5 \%)$ & $58(17.2 \%)$ & $18(24.7 \%)$ & 0.138 \\
\hline Postoperative blood transfusion, n (\%) & $297(74.1 \%)$ & $240(72.9 \%)$ & $57(79.2 \%)$ & 0.276 \\
\hline Total number of packed red blood cells, units & $4(0 ; 8)$ & $3(0 ; 7)$ & $6(2 ; 16)$ & 0.001 \\
\hline Total number of fresh frozen plasma, units & $2(0 ; 6)$ & $0(0 ; 6)$ & $4(0 ; 12)$ & 0.002 \\
\hline Total number of platelet concentrate, units & $0(0 ; 2)$ & $0(0 ; 2)$ & $2(0 ; 3)$ & $<0.001$ \\
\hline Postoperative status & & & & 0.156 \\
\hline Stable, $\mathbf{n}(\mathbf{\%})$ & $92(23.1 \%)$ & $73(22.3 \%)$ & $19(26.8 \%)$ & ---- \\
\hline Stable with low dose catecholamines, $\mathbf{n}(\mathbf{\%})$ & $244(61.3 \%)$ & $206(63.0 \%)$ & $38(53.5 \%)$ & ---- \\
\hline Stable with high dose catecholamines, $\mathbf{n}(\mathbf{\%})$ & $51(12.8 \%)$ & $41(12.5 \%)$ & $10(14.1 \%)$ & ---- \\
\hline IABP/ECLS with catecholamines, $\mathbf{n}(\mathbf{\%})$ & $10(2.5 \%)$ & $7(2.1 \%)$ & $3(4.2 \%)$ & ---- \\
\hline IABP without catecholamines, $\mathbf{n}(\mathbf{\%})$ & $1(0.3 \%)$ & $0(0.0 \%)$ & $1(1.4 \%)$ & ---- \\
\hline
\end{tabular}




\author{
Reintubation, n (\%) \\ Tracheotomy, n (\%) \\ Re-admission to the ICU, n (\%) \\ Re-admission postoperative days, $\mathrm{d}$ \\ Postoperative delirium, n (\%) \\ Postoperative myocardial infarction, n (\%) \\ TIA/Stroke (CT-proofed), n (\%) \\ CPR, n (\%) \\ Bronchopulmonary infection, $\mathbf{n}(\%)$ \\ Bacteriaemia/sepsis, n (\%) \\ Sternal wound infection, $\mathbf{n}(\%)$ \\ Atrial fibrillation, n (\%) \\ Ventilation time, $h$ \\ ICU time, $\mathrm{d}$ \\ Postoperative days, $\mathrm{d}$ \\ 7 d-Mortality, n (\%) \\ 30 d-Mortality, n (\%)
}

Hospital Mortality

$\begin{array}{cccc}71(17.3 \%) & 52(15.4 \%) & 19(26.0 \%) & 0.030 \\ 100(24.4 \%) & 68(20.2 \%) & 32(43.8 \%) & <0.001 \\ 39(9.5 \%) & 32(9.5 \%) & 7(9.6 \%) & 0.986 \\ 5(2 ; 8) & 5(2 ; 8) & 3.5(1.3 ; 13) & 0.878 \\ 75(18.3 \%) & 57(17.0 \%) & 18(24.7 \%) & 0.124 \\ 6(1.5 \%) & 4(1.2 \%) & 2(2.7 \%) & 0.290 \\ 95(23.2 \%) & 72(21.4 \%) & 23(31.5 \%) & 0.063 \\ 26(6.3 \%) & 22(6.5 \%) & 4(5.5 \%) & 1.000 \\ 58(14.1 \%) & 41(12.2 \%) & 17(23.3 \%) & 0.013 \\ 19(4.6 \%) & 17(5.0 \%) & 2(2.7 \%) & 0.547 \\ 6(1.5 \%) & 4(1.2 \%) & 2(2.8 \%) & 0.283 \\ 44(10.8 \%) & 38(11.3 \%) & 6(8.2 \%) & 0.436 \\ 64(19 ; 195) & 50(18 ; 162) & 134(29 ; 359) & <0.001 \\ 6(2 ; 12) & 5(2 ; 10) & 9(4 ; 19) & <0.001 \\ 10(7 ; 19) & 10(7 ; 18) & 12(7 ; 20) & 0.241 \\ 43(10.5 \%) & 37(11.0 \%) & 6(8.2 \%) & 0.485 \\ 67(16.3 \%) & 56(16.6 \%) & 11(15.1 \%) & 0.746 \\ 62(15.1 \%) & 51(15.1 \%) & 11(15.1 \%) & 0.288 \\ 32(51.6 \%) & 25(49.0 \%) & 7(63.6 \%) & ----- \\ 6(9.7 \%) & 5(9.8 \%) & 1(9.1 \%) & ----- \\ 2(3.2 \%) & 1(2.0 \%) & 1(9.1 \%) & ---- \\ 22(35.5 \%) & 20(39.2 \%) & 2(18.2 \%) & -----\end{array}$

Significant $\mathrm{p}$-values are indicated in bold. Quantitative data are presented as median with $25^{\text {th }}$ and $75^{\text {th }}$ percentiles. The symbol $\mathrm{n}$ indicates the number of patients in categorical data. Intra-aortic balloon pump is abbreviated to IABP, extracorporeal life support to ECLS, days to $\mathbf{d}$, intensive care unit to ICU, Hour to $\mathbf{h}$, transient ischemic attack to TIA, computed tomography to $\mathbf{C T}$, c-reactive protein to CPR, multiple organ failure to MOF.

Short- and long-term survival was satisfactory in both groups. The one-year ( $94 \%$ vs. $86 \%$ ), 3-year ( $90 \%$ vs. $86 \%$ ), 5-year ( $85 \%$ vs. $82 \%$ ), and 10 -year $(61 \%$ vs. $50 \%)$ survival rates were in the same range in both groups $(\mathrm{p}=0.784)$ (Fig.1). 


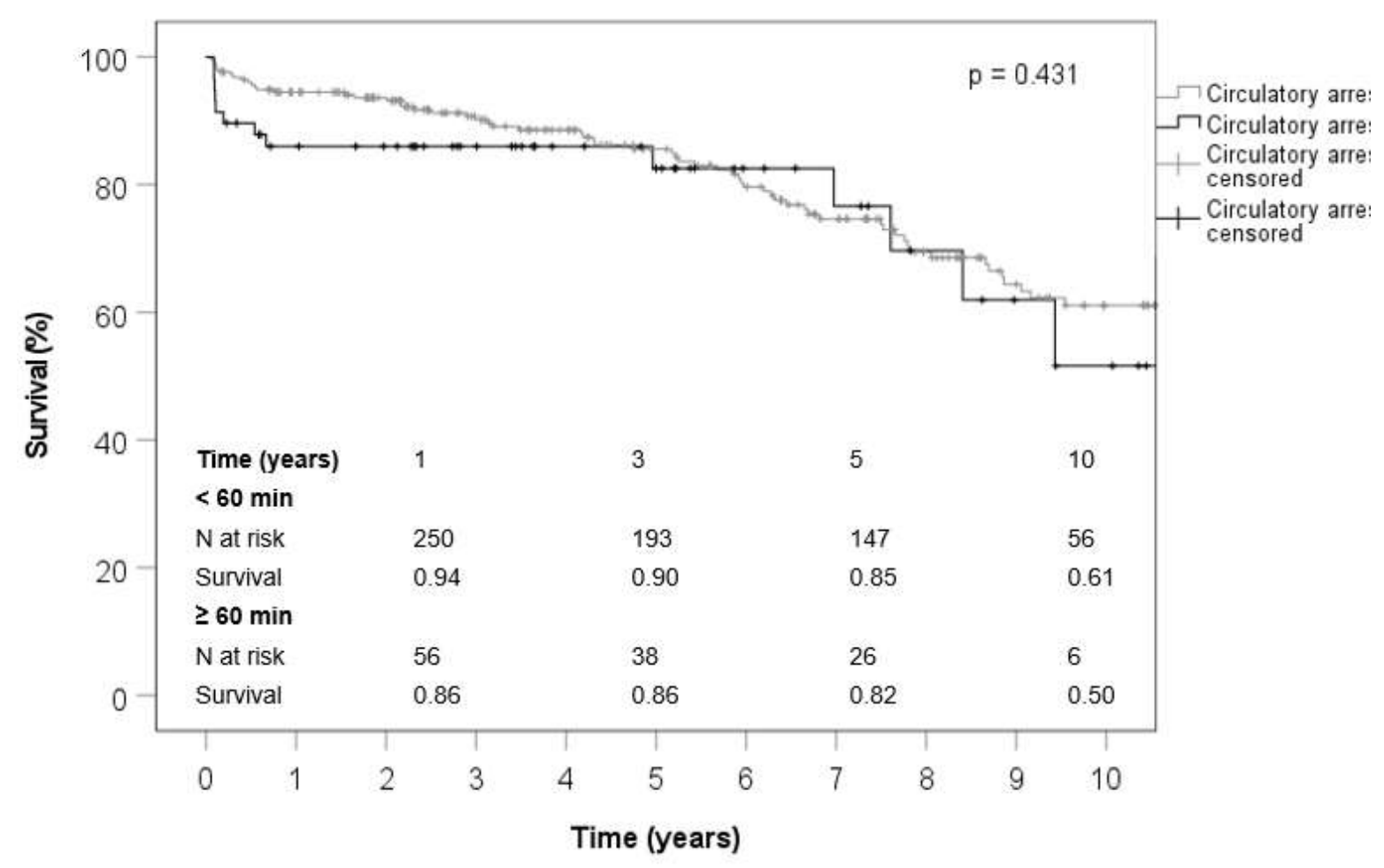

Figure 1: The estimated survival curves by Kaplan-Meier method

\section{Discussion}

In our study, the association between DHCA duration and clinical outcomes of 410 patients with AAAD was investigated. In total, 73 patients $(17.8 \%)$ were identified as those with a DHCA time equal or longer than 60 minutes and 337 patients $(82.2 \%)$ as those with a DHCA time less than 60 minutes.

Both groups were compared concerning their demographic, preoperative data. However, there were significant differences between both groups concerning the intra-, and postoperative data. Although the patients with longer DHCA have more complex aortic surgical procedures and correspondingly significant longer surgical duration, ICU time and postoperative in-hospital days, there was no significant difference between both groups concerning the 7-day and 30-day mortality and also long-term outcome.

In the literature, there are several studies and review articles about investigating the effect of the DHCA duration on clinical outcomes of patients during aortic surgery $[3,11-$ 13].

Our analysis demonstrated that patients undergoing longer DHCA presented a not significant higher rate of postoperative neurological events $(31.5 \%$ vs $21.4 \%, \mathrm{p}=0.06)$. In a large study of a national clinical registry, O'Hara et al. [4] suggested that cerebral perfusion using antegrade and retrograde cerebral perfusion strategies are associated with reduced death and stroke risk compared with hypothermic circulatory arrest without cerebral perfusion. The impact of DHCA duration and the potential effects of ACP on midterm quality of life (QoL) was assessed in a retrospective study of Immer et al. in 2004 [14]. In total, 363 patients with a thoracic aortic surgery were included in this study. 176 patients $(48.5 \%)$ of the cohort presented with an AAAD. The patients were divided into three groups according to the duration of DHCA ( $<20$ minutes, 20-29 minutes, and $\geq 30$ 
minutes). In-hospital data comparable to our study were assessed in this study, but a much shorter follow-up (2.4 \pm 1.2 years) was performed in all survivors. Immer et al. demonstrated that DHCA duration longer than 20 minutes, especially longer than 35 minutes, adversely affected mid-term QoL in their study patients. But the use of ACP, however, improved averaged QoL score and allows DHCA to be extended up to 30 minutes, without impairment in mid-term QoL. The median DHCA is 33 minutes in our patients. Although we did not assess the QoL in our study, the comparison between the survivors within our patient groups during a follow-up to 10 years confirm the by mentioned success of DHCA with adjunctive selective ACP by Immer et al..

In a retrospective study of Mazzeffi et al. [12] in 2012 the relationship between DHCA time and perioperative bleeding and coagulopathy was investigated in a cohort of 507 consecutive patients who had thoracic aortic surgery. Mazzeffi et al. estimated the degree of bleeding and coagulopathy using perioperative transfusion. In accordance to our study, they reported a significant association between DHCA time and RBC transfusion $(\mathrm{p}=$ 0.001). In contrast to our study, they could not find any significant association between DHCA time and FFP and platelet transfusion $(p=0.18$ and $p=0.06)$. Mazzeffi et al. reported found a dependency of the association between DHCA time and the amount of bleeding (RBC transfusion) on cardiopulmonary bypass (CPB) time. They stated a positive relationship between DHCA duration and bleeding for CPB time up to 180 minutes but no such relationship for considerably longer CPB times (300 to 360 minutes). In contrast to Mazzeffi et al., our data confirm an association between longer CPB time and the amount of bleeding.

The varying evidence on deep hypothermic circulatory arrest was dealt in a review article of Gupta et al. from 2018 [15]. In total, 17 original articles from 1999 to 2013 were reviewed in this article, which had various main foci like neuropsychological outcome after DHCA, cerebral protection during aortic surgery, and quality of life after DHCA with ACP. Gupta et al. demonstrated that there are controversial discussions about the safe duration of DHCA. Some authors have suggested that DHCA durations in a range of 20 to 25 minutes affect the surgical outcomes and the quality of life [14,16], while other authors in contrast reported that DHCA durations under 50 minutes are safe for performing of aortic arch interventions [16]. In a retrospective study with 656 patients, an increased incidence of postoperative stroke was reported as a result of DHCA durations of longer than 40 minutes [18]. In contrast, DHCA less than 60 minutes was demonstrated as an adequate cerebral protection technique in a comparably homogeneous and smaller study with 200 patients [18]. In a further review article the authors associated DHCA duration of longer than 49 minutes with a higher rate of stroke compared to the duration of 40 to 49 minutes [11]. Based on a multivariable analysis in this article, DHCA times equal and longer than 50 minutes significantly correlated with adverse outcomes and early death [11]. In comparison with some studies in the literature, our study included a homogenous and relatively large cohort of 410 patients with AAAD. Therefore, the surgical outcome of patients in two different DHCA times of under 60 minutes and equal and above 60 minutes could be investigated within one study with the similar surgical setup. Our patients with longer DHCA times were reintubated significantly more frequently and underwent common a tracheotomy. They had also a significantly longer ventilation time and ICU stay time. Nevertheless, we could not observe any effect of DHCA time on cardiac and neurologic outcomes after DHCA in terms of postoperative myocardial infarction, delirium, and TIA/stroke.

It is to be expected, that longer DHCA time is associated with a significant higher morbidity and mortality [12, 20,21]. But the current advances in surgical techniques, circulatory management, and postoperative care improve the early and late clinical outcome of patients with DHCA time of longer than 60 minutes [13]. 
The main limitations of our study were the retrospective design, the inhomogeneity of both patient groups without a propensity score matching analysis. Multivariable logistic regression analysis was performed based on this large sample size to adjust for known confounders, however, there remains a risk of unknown or not surveyed confounders.

\section{Conclusions}

Based on our 18-year single center experience, we investigated the effect of the DHCA duration on clinical outcomes in patients with AAAD. Our results confirmed that improvements in perioperative management including ACP allow a successful performance of surgical treatment of AAAD under DHCA with a duration of even longer than 60 minutes. Further prospective, multicentric, and randomized clinical studies with a larger group of patients are required to investigate in detail if in consideration of improved peri- and intraoperative management the duration of DHCA still has a strong effect on clinical outcomes in patients with AAAD.

\section{Patents: Not applicable.}

Supplementary Materials: Not applicable.

Author Contributions: “Conceptualization, C.F., J. C., J. S., L. H., G. E., M. S., G. L., T. P., J. C. and A. H.; methodology, C.F., J. C., J. S., L. H., G. E., M. S., G. L., T. P., J. C. and A. H.; software, Not applicable; validation, Not applicable; formal analysis, C. F.; investigation, M. S.R.; resources, Not applicable.; data curation, C. F. and A. H.; writing-original draft preparation, M. S.R., C.F., and A. H.; writing-review and editing, M. S.R., C.F., J. C., J. S., L. H., G. E., M. S., G. L., T. P., J. C. and A. H..; visualization, C.F.; supervision, A.H.; project administration, A.H.; funding acquisition, Not applicable. All authors have read and agreed to the published version of the manuscript."

Funding: Not applicable.

Institutional Review Board Statement: This retrospective single-centre cohort study was conducted in accordance with the Declaration of Helsinki (as revised in 2013) and approved by the local ethics committee of Christian-Albrechts University of Kiel (No. D417/17).

Informed Consent Statement: Written informed consent for this retrospective analysis was waived

Data Availability Statement: The data presented in this study are available on request from the corresponding author.

Acknowledgments: Not applicable.

Conflicts of Interest: The authors declare no conflict of interest."

\section{Appendix A}

Not applicable.

\section{Appendix B}

Not applicable.

\section{References}

1. Taylor KM. Brain damage during open-heart surgery. Thorax. 1982;37:873-6.

2. Griepp RB, Stinson EB, Hollingsworth JF, Buehler D. Prosthetic replacement of the aortic arch. J Thorac Cardiovasc Surg. 1975;70:1051-63.

3. Tian DH, Wan B, Bannon PG, Misfeld M, LeMaire SA, Kazui T, et al. A meta-analysis of deep hypothermic circulatory arrest alone versus with adjunctive selective antegrade cerebral perfusion. Ann Cardiothorac Surg. 2013;2:261-70. 
4. O'Hara D, McLarty A, Sun E, Itagaki S, Tannous H, Chu D, Egorova N, Chikwe J. Type-A Aortic Dissection and Cerebral Perfusion: The Society of Thoracic Surgeons Database Analysis. Ann Thorac Surg. 2020 Nov;110(5):1461-1467.

5. Cao L, Guo X, Jia Y, Yang L, Wang H, Yuan S. Effect of Deep Hypothermic Circulatory Arrest Versus Moderate Hypothermic Circulatory Arrest in Aortic Arch Surgery on Postoperative Renal Function: A Systematic Review and MetaAnalysis. J Am Heart Assoc. 2020;9:e017939.

6. Okita Y, Takamoto S, Ando M, Morota T, Matsukawa R, Kawashima Y. Mortality and cerebral outcome in patients who underwent aortic arch operations using deep hypothermic circulatory arrest with retrograde cerebral perfusion: no relation of early death, stroke, and delirium to the duration of circulatory arrest. J Thorac Cardiovasc Surg. 1998;115:12938.

7. Kumral E, Yüksel M, Büket S, Yagdi T, Atay Y, Güzelant A. Neurologic complications after deep hypothermic circulatory arrest: types, predictors, and timing. Tex Heart Inst J. 2001;28:83-8.

8. Schoeneich F, Rahimi-Barfeh A, Grothusen C, Cremer J. Transatrial left-ventricular cannulation in acute aortic dissection type A: a novel cannulation technique. Eur J Cardiothorac Surg. 2015;48:e51-2.

9. Salehi Ravesh M, Salem M, Lutter G, Friedrich C, Walter V, Puehler T, et al. Comparison of outcomes in DeBakey type I versus DeBakey type II aortic dissection: a 17-year single center experience. Journal of Thoracic Disease. 2021.

10. Salehi Ravesh M, Rusch R, Friedrich C, Teickner C, Berndt R, Haneya A, et al. Impact of patients' age on short and longterm outcome after carotid endarterectomy and simultaneous coronary artery bypass grafting. Journal of cardiothoracic surgery. 2019;14:109.

11. Ziganshin BA, Elefteriades JA. Deep hypothermic circulatory arrest. Ann Cardiothorac Surg. 2013;2:303-15.

12. Mazzeffi M, Marotta M, Lin H-M, Fischer G. Duration of deep hypothermia during aortic surgery and the risk of perioperative blood transfusion. Ann Card Anaesth. 2012;15:266-73.

13. Moeller E, Nores M, Stamou SC. Repair of Acute Type-A Aortic Dissection in the Present Era: Outcomes and Controversies. Aorta (Stamford). 2019;7:155-62.

14. Immer FF, Lippeck C, Barmettler H, Berdat PA, Eckstein FS, Kipfer B, et al. Improvement of quality of life after surgery on the thoracic aorta: effect of antegrade cerebral perfusion and short duration of deep hypothermic circulatory arrest. Circulation. 2004;110:II250-5.

15. Gupta P, Harky A, Jahangeer S, Adams B, Bashir M. Varying Evidence on Deep Hypothermic Circulatory Arrest in Thoracic Aortic Aneurysm Surgery. Tex Heart Inst J. 2018;45:70-5.

16. Ergin MA, Uysal S, Reich DL, Apaydin A, Lansman SL, McCullough JN, Griepp RB. Temporary neurological dysfunction after deep hypothermic circulatory arrest: a clinical marker of long-term functional deficit. Ann Thorac Surg. 1999;67:1887-90; discussion 1891-4.

17. Elefteriades JA. What is the best method for brain protection in surgery of the aortic arch? Straight DHCA. Cardiol Clin. 2010;28:381-7.

18. Svensson LG, Crawford ES, Hess KR, Coselli JS, Raskin S, Shenaq SA, Safi HJ. Deep hypothermia with circulatory arrest. Determinants of stroke and early mortality in 656 patients. J Thorac Cardiovasc Surg. 1993;106:19-28; discussion 28-31.

19. Ergin MA, Galla JD, Lansman SL, Quintana C, Bodian C, Griepp RB. Hypothermic circulatory arrest in operations on the thoracic aorta. Determinants of operative mortality and neurologic outcome. J Thorac Cardiovasc Surg. 1994;107:78897; discussion 797-9.

20. Cooper WA, Duarte IG, Thourani VH, Nakamura M, Wang N-P, Brown W, et al. Hypothermic circulatory arrest causes multisystem vascular endothelial dysfunction and apoptosis. Ann Thorac Surg. 2000;69:696-702.

21. Harrington DK, Lilley JP, Rooney SJ, Bonser RS. Nonneurologic morbidity and profound hypothermia in aortic surgery. Ann Thorac Surg. 2004;78:596-601. 